\title{
A Regulação do cfm e os Desafios na Aplicabilidade de Soft Law em Casos de \\ TERMinalidade
}

\section{CFM regulation and Challenges in Soft Law Applicability in Terminality Cases}

\author{
Regulación del CFM Y Desafíos en la \\ Aplicabilidad del Soft Law en Casos de \\ TERMINALIDAD
}

Taysa Schiocchet Suéllyn Mattos de Aragão**

\begin{abstract}
1 Introdução. 2 Soft Law e Bioética: status da regulamentação interna sobre terminalidade da vida. 3 Implicações das resoluções do CFM no enquadramento normativo sobre terminalidade. 4 Desafios para aplicabilidade das normas do CFM acerca da terminalidade. 5 Aposta nas boas práticas para superação dos obstáculos. 5.1 Instituição de protocolos, diretrizes, rotinas, procedimentos operacionais padrão e/ou programas de cuidados paliativos nas instituições que prestem atendimento a pacientes nessa condição. 5.2 Utilização de indicadores clínicos objetivos e mensuráveis
\end{abstract}

Professora Adjunta da Faculdade de Direito e do Programa de Pós-Graduação em Direito da UFPR. Doutorado em Direito, com período de estudos doutorais na Université Paris I e na FLACSO, Buenos Aires. Pós-doutorado pela Universidad Autónoma de Madrid (UAM). Professora visitante da Université Paris X. Advogada. Coordenadora da Clínica de Direitos Humanos da UFPR e da equipe do Blog Fala Direito Comigo. Curitiba, PR, BR. E-mail: <taysa_sc@hotmail.com>. http://orcid.org/0000-0002-6703-9036

** Doutoranda em Direito pela Universidade Federal do Paraná - UFPR (2021). Mestre em Saúde Coletiva pela UFPR (2019). Especialista em Medicina do Trabalho pela UFPR (2010), com título conferido pela AMB/ANAMT. Médica pela Universidade do Vale do Itajaí - UNIVALI (2008). Pesquisadora associada da Clínica de Direitos Humanos Biotecjus UFPR; do grupo de pesquisa Política, Avaliação e Gestão em Saúde da UFPR e do grupo de pesquisa em Direitos Humanos do Ministério Público Estadual do Paraná - MPPR. Médica da UFPR e do MPPR. Curitiba, PR, BR. Email:<suellyn@ufpr.br>.https://orcid.org/0000-0002-4497-1621 
para caracterização de estado de terminalidade. 5.3 Utilização de escalas instrumentais padronizadas e validadas cientificamente para definição de prognóstico de pacientes em situação de paliatividade. 5.4 Previsão de ações globais que contemplem toda linha de cuidado da terminalidade. 5.5 Formalização de termo para inclusão do paciente em protocolo de paliatividade. 5.6 Estabelecimento de regras sobre a definição da pessoa responsável por decidir pelo paciente em caso de impossibilidade de manifestação direta de sua vontade (estado de inconsciência e congêneres). 5.7 Registro em ata de reuniões com familiares. 6 Conclusão. Referências.

\section{RESUMO}

Objetivo: O objetivo do presente estudo foi analisar o modo como as principais soft law nacionais relativas à terminalidade vem sendo (ou não) adotadas na prática médica, indicando caminhos para superação de entraves em sua aplicação.

Metodologia: Utilizou-se uma abordagem qualitativa, descritiva e exploratória, com revisão bibliográfica de artigos, ordenamento jurídico e obras doutrinárias.

Resultados: $\mathrm{Na}$ análise, foram encontrados desafios estruturais, institucionais, técnicojurídicos e sociais relativos à terminalidade.

Contribuições: A partir dos resultados, foram propostas medidas de potencial resolutivo: instituição de protocolos de paliatividade; utilização de indicadores para caracterização da terminalidade; utilização de escalas para definição de prognóstico; previsão de ações que contemplem toda linha de cuidado; formalização da inclusão de paciente em protocolo; estabelecimento de regras sobre a definição do representante legítimo, em caso de impossibilidade de manifestação direta da vontade do paciente, e registro em ata de reuniões realizadas com familiares.

Palavras-chave: Biodireito. Bioética. Terminalidade. Softlaw. Conselho Federal de Medicina. Resoluções.

\section{ABSTRACT}

Objective: The objective of the present study was to analyze how the main national soft laws related to terminality have been (or not) adopted in medical practice, indicating ways to overcome obstacles in their application.

Methodology: We use a qualitative, descriptive and exploratory approach, with bibliographic review of articles, legal order and clinical works.

Results: In the analysis, structural, institutional, technical-legal and social challenges related to terminality were found.

2 - R. Opin. Jur., Fortaleza, ano 19, n. 30, p.1-34, jan./abr. 2021 
Contributions: Based on results, measures of potential resolution were proposed: institution of palliative protocols; use of indicators to characterize terminality; use of scales to define prognosis; prediction of actions that contemplate the entire line of care; formalization of the inclusion of a patient in a protocol; establishment of rules on the definition of the legitimate representative, in case of impossibility of direct manifestation of the patient's will, and recording in minutes of meetings held with family members.

Keywords: Biolaw. Bioethics. Terminality. Softlaw. Federal Council of Medicine. Resolutions.

\section{RESUMEN}

Objetivo: El objetivo del presente estudio fue analizar cómo se han adoptado (o no) en la práctica médica las principales soft law nacionales relacionadas con la terminalidad, indicando formas de superar obstáculos en su aplicación.

Metodologia: Se utilizó un enfoque cualitativo, descriptivo y exploratorio, con revisión bibliográfica de artículos, ordenamiento jurídico y construcciones doctrinales.

Resultados: El análisis encontró desafíos estructurales, institucionales, técnico-legales y sociales relacionados con la terminalidad.

Contribuciones: Con base en los resultados, se propusieron medidas con potencial de resolución: institución de protocolos paliativos; uso de indicadores para caracterizar la terminalidad; uso de escalas para definir el pronóstico; predicción de acciones que contemplen toda la línea de atención; formalización de la inclusión del paciente en protocolo; establecimiento de reglas sobre la definición de representante legítimo, en caso de imposibilidad de manifestación directa de la voluntad del paciente, y registro en acta de reuniones mantenidas con familiares.

Palabras clave: Bioderecho. Bioética. Terminalidad. Soft Law. Consejo Federal de Medicina. Resoluciones.

\section{INTRODUÇÃO}

As questões que gravitam em torno da vida e de seu inelutável desfecho provocam acalorados debates por parte de grupos sociais e de especialistas dos mais variados campos do conhecimento. Juristas, médicos, sociólogos, biólogos, filósofos e cientistas buscam respostas às complexas questões que envolvem o início e o fim do ser (GOLDINHO, 2017). 
Não há uma resposta única, reducionista e unânime. Em pesquisa empírica, Fraga, Vilas Boas e Mendonça (2012) constataram que, para a maioria dos médicos entrevistados, o conceito de terminalidade da vida diz respeito à morte encefálica (ME). As atuais diretrizes para o diagnóstico de ME foram delineadas em 1981, durante os trabalhos da Comissão Presidencial para o estudo de problemas éticos em Medicina nos EUA. A partir de então, os critérios tornaram-se mais seguros, incluindo a identificação adequada do paciente e da causa do coma, sua irreversibilidade e a exclusão de causas metabólicas e de intoxicação exógena entre os parâmetros (GUIDELINES..., 1981; WIJDICKS et al., 2010). Com objetivo de uniformizar esses critérios, a Associação Americana de Neurologia (AAN) organizou um comitê que, em 1995, publicou revisão da literatura médica baseada em graus de evidência científica de mais de 200 artigos sobre ME, o que possibilitou a definição dos critérios utilizados atualmente (WIJDICKS, 1995).

Em âmbito nacional, a matéria é regulada pela Resolução $\mathrm{n}^{\circ}$ 1.826/2007, que dispõe sobre a legalidade e o caráter ético da suspensão dos procedimentos de suportes terapêuticos quando da determinação de morte encefálica de indivíduo não-doador de órgãos (CFM, 2007) e pela Resolução n²173/2017, que define, propriamente, os critérios do diagnóstico de morte encefálica (CFM, 2017).

Inobstante, é inegável que o universo que circunda o óbito envolve muitas outras disputas éticas, morais, espirituais, biológicas, sociais, políticas e jurídicas, para além do reducionismo biológico. Nesse sentido, Carvalho et al. (2001) afirmam que, na prática, a identificação do paciente terminal é complexa e não envolve unicamente um raciocínio lógico, diferentemente do que ocorre com a morte cerebral, para a qual existem protocolos capazes de definir o seu diagnóstico.

O aumento da expectativa de vida da população mundial, aliado ao desenvolvimento tecnológico e farmacológico, tem provocado uma mudança nas causas e nas formas de morrer. Patologias que causavam uma morte rápida até o século passado adquirem, no século XXI, a condição de doenças crônicas, com sobrevida de décadas. Assim, as discussões sobre terminalidade da vida têm se modificado e, atualmente, alcançam o status quo de dilema bioético, problema moral, demanda jurídica, questão médica e assunto comercial (DADALTO, 2019; STEINHAUSER et al., 2000).

Estudiosos de destaque a respeito do tema, podem ser mencionados Jean Robert Debray, Robert Twycross, Elisabeth Kubler-Ross, Miguel Kottow, Fermin Roland Schramm, Kathryn Mannix, no campo médico, e Daniel Callahan, Christian Byk, Xavier Dijon, Maria de Fátima Freire de Sá, Débora Diniz, Léo Pessini e Luciana Dadalto, no campo sociojurídico. Na esfera biossocial, os principais conteúdos e pontos controversos debatidos dizem respeito a:

a) disputas éticas, morais e filosóficas sobre o início e o fim da vida;

4 - R. Opin. Jur., Fortaleza, ano 19, n. 30, p.1-34, jan./abr. 2021 
b) dignidade humana e autonomia privada no evento morte e;

c) cuidados paliativos.

Já no espaço jurídico, a garantia ao princípio da dignidade humana; a (in) constitucionalidade e a (des) criminalização das práticas de eutanásia, ortotanásia, distanásia e mistanásia; a garantia de fornecimento de acesso aos cuidados paliativos e os conflitos relativos às diretivas antecipadas de vontade figuram como alguns dos temas mais frequentes.

Cumpre-nos esclarecer que o presente artigo não se volta ao debate conceitual, semântico e epistêmico (filosófico, moral e biomédico) nem aos conflitos jurídicos relativos às diferentes formas de óbito (ortotanásia ${ }^{1}$, distanásia $^{2}$, mistanásia $^{3}$ e eutanásia ${ }^{4}$ ), vez que tais litígios já vêm sendo explorados com profundidade por diversos escritos na literatura mundial e nacional.

As abordagens e tomadas de decisões técnicas, éticas e jurídicas na terminalidade da vida têm sido objeto constante de preocupação nos tribunais, especialmente quanto às diretivas antecipadas, ${ }^{5-6-7}$ e nos corredores hospitalares, sobretudo em unidades de urgência e emergência e de terapia intensiva. $\mathrm{O}$ fascinante desenvolvimento tecnológico torna possível prolongar a existência até limites ainda não totalmente dominados, o ponto reverso é a possibilidade de deterioração progressiva da qualidade e da dignidade da vida humana em virtude de demandas, escolhas e interferências pouco catedráticas.

${ }^{1}$ Conforme Junges et al. (2010), a ortotanásia significa a morte correta. Traduz a morte desejável, na qual não ocorre o prolongamento da vida, artificiosamente, por meio de procedimentos que acarretam aumento do sofrimento e alteram o processo natural do morrer. Está associada à morte em tempo adequado, chamada de boa morte ou morte digna.

${ }^{2}$ Segundo Junges et al. (2010), a distanásia está em contraposição à ortotanásia, pois tem por objetivo prolongar a vida a qualquer custo, mesmo com sofrimento do paciente. Trata-se de prática contestada e não recomendada, pois delonga a agonia dos pacientes sem que esses tenham expectativa de cura ou melhora na qualidade de vida.

${ }^{3}$ Consoante Ferreira (2019), a mistanásia é um neologismo cunhado em 1989 por Márcio Fabri dos Anjos, bioeticista brasileiro, que provém da etimologia grega (mys=infeliz; thanathos $=$ morte) e trata da morte infeliz, miserável, precoce e evitável. Possui relação com o social e os determinantes sociais da saúde. É gerada pela pobreza estrutural, violência, drogadição, subfinanciamento da saúde pública, entre tantos outros fatores que implicam na ausência de um ambiente favorável e de condições colaborativas mínimas que garantam uma vida digna.

${ }^{4}$ De acordo com Junges et al. (2010), a eutanásia é o processo de morte de um enfermo por intervenção. Nessa situação, a causa imediata da morte é produzida com o objetivo de aliviar ou evitar um sofrimento insuportável. Trata-se, portanto, de prática para abreviar a vida. No Brasil, é ilegal.

${ }^{5}$ TJ-SP - AC: 10009381320168260100 SP 1000938-13.2016.8.26.0100, Relator: Mary Grün, Data de Julgamento: 10/04/2019, 7a Câmara de Direito Privado, Data de Publicação: 11/04/2019.

${ }^{6}$ TJ-DF 07073272220198070000 - Segredo de Justiça 0707327-22.2019.8.07.0000, Relator: ANGELO PASSARELI, Data de Julgamento: 06/08/2019, 1 ${ }^{a}$ Câmara Cível, Data de Publicação: 09/08/2019.

${ }^{7}$ TJ-SP - AC: 10009381320168260100 SP 1000938-13.2016.8.26.0100, Relator: Mary Grün, Data de Julgamento: 10/04/2019, 7a Câmara de Direito Privado, Data de Publicação: 11/04/2019. 
São questões que envolvem muitas perspectivas de apreciação, abrangem os interesses e desejos dos pacientes, seus familiares, profissionais de saúde, sociedade, instituições sanitárias e órgãos forenses e de controle.

Qual seria então o principal desafio relacionado à regulação ou, de modo mais específico, ao cumprimento de regramentos, nacionais ou internacionais, a respeito da terminalidade? Aparentemente, o ponto mais sensível se refere a algumas dificuldades práticas encaradas nos serviços de saúde: manejar adequadamente as alterações fisiológicas e sintomatológicas de doentes, atender aos anseios de pacientes e familiares e, simultaneamente, respeitar às normativas vigentes, eis o grande desafio dos profissionais de saúde que assistem enfermos em fase de paliatividade.

Conceitos de ortotanásia, distanásia e mistanásia, bem explorados e delineados do ponto de vista teórico, parecem sobrepor-se em um embaralhado nebuloso de quadros clínicos, exames, documentos, familiares, dramas e normas. Suas diferenças e limites podem ser de sutileza irreconhecível na prática. Nesse contexto, a Morte Digna (GODINHO, 2017; DADALTO, 2019) tem sido apontada como ideário de solução dos conflitos e buscada via construção de instrumentos legais e normativos no sentido de pacificar e uniformizar, tanto quanto possível, a prestação dos cuidados nas proximidades da morte.

Aqui exsurge o espaço de saber em que pretende colaborar o presente artigo. A proposta é a de analisar, brevemente, o modo como os principais instrumentos normativos internos de soft law relativos à terminalidade vem sendo (ou não) adotados na prática médica e indicar possíveis caminhos para a superação de eventuais entraves identificados para sua aplicabilidade. Para atingir o objetivo proposto será adotada uma abordagem qualitativa, descritiva e exploratória. $\mathrm{O}$ método elegido é o indutivo, por meio da realização de revisão bibliográfica de artigos, ordenamento jurídico e obras doutrinárias.

Inicialmente, apresentamos breve comentário sobre a natureza jurídica e as características da soft law no contexto bioético e, mais especificamente, da terminalidade. $\mathrm{Na}$ sequência, apontamos os aspectos substanciais de algumas das principais normas nacionais acerca do tema, em especial as Resoluções do CFM $n^{\circ} 1.805 / 06, \mathrm{n}^{\circ}$ 1.995/2012 e $\mathrm{n}^{\circ}$ 2.156/2016. Posteriormente, elencamos os desafios na aplicabilidade desses estatutos e, por fim, sugerimos a aposta em boas práticas como possibilidade para sua superação.

\section{SOFT LAW E BIOÉTICA: STATUS DA REGULAMENTAÇÃO INTERNA SOBRE TERMINALIDADE DA VIDA}

O sistema jurídico é formado por diferentes tipos de normas. Tradicionalmente, a fonte por excelência, ao menos nos sistemas da civil law, é a lei, ou seja, uma norma 6 - R. Opin. Jur., Fortaleza, ano 19, n. 30, p.1-34, jan./abr. 2021 
escrita, coercitiva, sancionatória e produzida pelo Estado, mais especificamente, pelo Poder Legislativo. Ocorre que, além das leis, em sentido estrito, existem outras fontes normativas que compõem o universo jurídico de um dado país, ainda que elas não tenham sido produzidas pelas vias formais do Poder Legislativo estatal. A esse fenômeno convencionou-se chamar pluralismo jurídico.

Denominadas de soft law, em oposição à hard law, elas emergem de maneira mais expressiva no âmbito do direito internacional. São normas exaradas por entidades internacionais, seja no âmbito de organizações multilaterais, enquanto pessoas jurídicas de direito Internacional Público, seja no de organizações regulatórias, não necessariamente ligadas às organizações internacionais de Direito Público. Diante de uma certa insuficiência dos mecanismos hard law, a chamada soft law surge para regular, de alguma forma, os temas que surgem de acordo com o desenvolvimento tecnológico e social, dada a sua flexibilidade e celeridade de tramitação. Suas principais aparições no Direito Internacional se dão por meio de declarações, recomendações, cartas, códigos, diretrizes e resoluções (SHELTON, 2008; GUZMAN; MEYER, 2010). ${ }^{8}$

A acepção mais corrente de soft law compreende as normas de valor normativo menos constringente, em comparação às normas jurídicas tradicionais, seja porque os instrumentos que as abrigam não detêm o status de 'norma jurídica', ou os "seus dispositivos, ainda que insertos no quadro dos instrumentos vinculantes, não criam obrigações de direito positivo aos Estados, ou não criam senão obrigações pouco constringentes." (SHELTON, 2008; MAZZUOLI, 2010, p. 140).

A regulação na órbita internacional torna-se prioritária quando determinados temas ultrapassam o espaço nacional isolado pelos limites da soberania estatal. Nesse contexto, como resposta às preocupações oriundas das questões relacionadas aos avanços biotecnológicos na prática clínica e na pesquisa, surge um grande número de documentos internacionais de bioética. E os mecanismos soft constituem uma alternativa real. Especialmente porque tratam de problemas complexos e em rápida mudança para os quais a lei não oferece orientação. $O$ conteúdo desses documentos soft se refere a normas "eminentemente principiológicas e regras mais ou menos vagas, às vezes, ambíguas e difíceis de serem aplicadas aos casos concretos." (SCHIOCCHET, 2010, p. 72).

\footnotetext{
${ }^{8}$ Segundo Nasser (2006, p. 25) elas podem aparecer ainda como normas, jurídicas ou não, de linguagem vaga ou de conteúdo variável ou aberto ou, ainda, que tenham caráter principiológico ou genérico, impossibilitando a identificação de regras claras e específicas; normas que prevejam mecanismos de solução de controvérsias, como a conciliação e a mediação; atos concertados entre os Estados que não adquiram a forma de tratados e que não sejam obrigatórios; atos das organizações internacionais que não sejam obrigatórios; instrumentos produzidos por entes não-estatais que consagrem princípios orientadores do comportamento dos sujeitos de Direito Internacional e que tendam a estabelecer novas normas jurídicas.
} 
De qualquer sorte, autores como Andorno (2007) destacam que a soft law foi a melhor, senão a única opção disponível para a Bioética global, na medida em que as incertezas foram crescendo no tocante à complexidade do sistema que define os problemas dessa área do conhecimento. De fato, os instrumentos da soft law "podem ser tão persuasivos e influentes quanto os tratados, endurecendo, num certo sentido, o soft da norma. Esse endurecimento se daria mais pela persuasão que pela coerção.” (SCHIOCCHET, 2010, p. 71).

Fato é que esse fenômeno normativo denominado soft law passou por inúmeras mudanças nos últimos anos. Dois aspectos merecem destaque: abrangência e vinculatividade. Antes a soft law tinha presença mais proeminente apenas na esfera internacional, por meio de acordos, princípios e declarações sem caráter juridicamente vinculativos. Atualmente, ela já compõe a arquitetura regulatória no âmbito interno dos países, por meio de resoluções, instruções normativas e uma infinidade de documentos regulatórios infralegais. O segundo aspecto diz respeito ao fato de que muitos desses documentos, de origem nacional ou internacional, têm gerado obrigações vinculativas, à exemplo da lei (hard law), com aplicação inclusive pelos tribunais.

Autores como Campbell e Glass (2001) analisaram, no âmbito da bioética, como a soft law é criada, como é seguida pelos profissionais da área e como é aceita pelos tribunais. Com relação ao primeiro aspecto, eles destacam que a soft law constitui-se como autorregulação ou autogoverno, por parte dos profissionais (médicos e pesquisadores, no caso), para evitar demandas judiciais. Quanto ao segundo aspecto referem que a observância dessas normas depende do amplo reconhecimento pelos pares, bem como da efetiva adoção das suas orientações na prática, referendando, por assim dizer, a norma. Por fim, acerca da adoção da soft law pelos tribunais, os pesquisadores referem que a análise judicial ultrapassa os dois aspectos anteriores, devendo assegurar que as normas da soft law estejam de acordo com as obrigações exigidas pela lei. Para isso - afastar ou aplicar a soft law - o tribunal avalia dois aspectos: primeiro, se a norma reflete padrões éticos internacionais e, segundo, se contraria leis locais. Como nem sempre é possível a temporalidade da lei acompanhar as rápidas e constantes mudanças, notadamente em áreas da bioética como a genética, os tribunais muitas vezes ficam sem opção a não ser aceitar a soft law pois a legislação, em contraponto, é incompleta, imprecisa ou menos rigorosa (CAMPBELL; GLASS, 2001, p. 481).

Em conclusão, para que a soft law seja, de fato, vinculativa, ela depende do crivo da interpretação judicial ou legislativa Assim, uma vez aceita e aplicada pelo tribunal, a soft law adquire normatividade legal. Exatamente por isso e para evitar a ampla autorregulação por parte dos profissionais, o tribunal não pode simplesmente presumir a adequação da soft law à legislação vigente. Do mesmo modo, cumpre ao tribunal 
perceber que a apreciação puramente legal tenderia a ignorar as rápidas transformações no campo da bioética e, portanto, viabilizaria a análise de apenas algumas, não todas, as questões de fundo (CAMPBELL; GLASS, 2001, p. 484-489).

Com essa incorporação paulatina de instrumentos da soft law pelos tribunais, muitos dos consensos mínimos que se conseguiu estabelecer no âmbito global, expressos em instrumentos tanto da hard law quanto da soft law, estão presentes no direito interno. Especificamente no campo da Bioética esses instrumentos são particularmente numerosos e influentes, e cumprem não apenas uma função de harmonização normativa, global e nacional, mas também de orientação de condutas e práticas na área da saúde. No Brasil, essa função é protagonizada por órgãos como o Ministério da Saúde (MS), a Agência Nacional de Vigilância Sanitária (ANVISA), o Conselho Nacional de Saúde (CNS) e o Conselho Federal de Medicina (CFM).

Assim, influenciados por essa estrutura flexível, esses organismos produzem normativas, em princípio deontológicas ou infralegais, mas com força normativa na prática. Além disso, existe todo um conjunto de instituições regulatórias, organismos de avaliação e controle, assim como normas de direito interno que, de algum modo, refletem o espírito das diretrizes internacionais em bioética e ética da pesquisa. Esse conjunto normativo nacional pode estar representado nos códigos profissionais deontológicos, nas orientações dos comitês de revisão ética de protocolos, nos órgãos estatais que controlam determinadas condutas, em documentos institucionais, assim como na legislação pertinente (SCHIOCCHET, 2010, p. 73).

A soft law, no âmbito interno, permite maior flexibilidade jurídica e orientação à tomada de decisão. Na esfera judicante, estimula as soluções amigáveis, negociações, pactos, mediações e arbitragens. Além disso, prevalece o caráter educativo ao repressivo, com a finalidade de reduzir a existência de conflitos, mas sem excluir a aplicação de sanções. Na esfera administrativa, os indícios de aceitação e efetivo uso dos instrumentos flexíveis se torna mais evidente. Suas regulações, que não constituem leis propriamente, possuem o mesmo efeito que normas emanadas pelo órgão legislativo, repercutindo na sociedade em geral. Como exemplo, esses organismos (MS, ANVISA, CNS) ganham atuação mais abrangente e diversificada, via atos normativos, fiscalizadores, decisórios, condutores e autorizadores, por exemplo.

Interessa para esse texto, particularmente, as resoluções produzidas pelo Conselho Federal de Medicina. O CFM, como ente autárquico da administração pública indireta possui, de acordo com as suas atribuições legais estabelecidas pelo Decreto-lei $n^{\circ} 7.955 / 45$, competência para editar atos normativos, como instruções, portarias, resoluções. Estas últimas, objeto de análise, possuem, na prática, uma expressiva capacidade vinculatória em relação ao público alvo, qual seja, os médicos. 
$\mathrm{Na}$ tentativa de solucionar conflitos na área da saúde e diante da omissão legislativa sobre temas bioéticos, o CFM supre, ainda que de forma parcial e de certo modo limitada (dependente de interpretação judicial ou legislativa), essa ausência normativa editando resoluções, em princípio deontológicas, mas com alto grau de aplicabilidade e eficácia. É claro que as resoluções do CFM não são lei, mas servem para responsabilização administrativa e suporte para decisões judiciais, se inserindo no sistema jurídico brasileiro como uma verdadeira fonte normativa.

O Conselho Federal de Medicina, na edição de suas resoluções, se utiliza dos padrões propostos pela soft law, a fim de orientar conduta de médicos sobre certos procedimentos, sobretudo no que se refere à sua conduta ética. São diversos os temas de impacto social que constituem alvo dessas resoluções a fim de restringir abusos, impor limites e preencher algumas omissões. À título exemplificativo, destacamos as seguintes resoluções do CFM: $n^{\circ}$ 2.265/2019 (cuidado específico à pessoa com incongruência de gênero ou transgênero); $\mathrm{n}^{\circ}$ 2.232/2019 (recusa terapêutica por pacientes e objeção de consciência na relação médico-paciente); $\mathrm{n}^{\circ}$ 2.168/2017 (técnicas de reprodução humana assistida); $\mathrm{n}^{\circ}$ 2.156/2016 (admissão e alta em UTI), $\mathrm{n}^{\circ}$ 2.144/2016 (vontade da gestante e autonomia do médico em procedimento de parto), $\mathrm{n}^{\circ}$ 2.113/2014 (uso compassivo do canabidiol), $\mathrm{n}^{\circ} 1.995 / 12$ (diretivas antecipadas de vontade); $\mathrm{n}^{\circ}$ 1.805/2006 (fase terminal de enfermidades graves e incuráveis).

A apropriação dessa função legiferante por um ente da administração indireta, como o CFM, revela a incapacidade do Poder Legislativo brasileiro tratar de assuntos complexos e sensíveis, como os bioéticos. Contudo, isso não impede os questionamentos no âmbito interno quanto à legalidade das resoluções do CFM em suprir a omissão do Poder Legislativo pela via de um direito infralegal, regulatório ou flexível, como a soft law.

Em síntese, se, por um lado, a força normativa da soft law é, como regra geral, questionada e limitada pela ausência de vínculo estatal-legal, por outro, cada vez mais, juristas e o próprio sistema têm reconhecido a força normativa desses documentos, seja pela via do Poder Judiciário, Executivo ou Legislativo, e os incorporado em suas práticas. Nesse cenário, nos interessa analisar particularmente as resoluções do CFM aplicáveis a casos envolvendo a terminalidade da vida, morte digna e cuidados paliativos, as quais, nem sempre adotam textos explícitos a respeito dessa temática.

\section{IMPLICAÇÕES DAS RESOLUÇÕES DO CFM NO ENQUADRAMENTO NORMATIVO SOBRE TERMINALIDADE}

No contexto nacional, as principais soft law de conteúdo pertinente ao enquadramento normativo sobre a terminalidade da vida foram editadas pelo Conselho 
Federal de Medicina. No presente manuscrito, abordaremos aquelas que consideramos primordiais à discussão do tema: Resolução $\mathrm{n}^{\circ} 1.805 / 06, \mathrm{n}^{\circ} 1.995 / 2012$ e $\mathrm{n}^{\circ}$ $2.156 / 2016$.

A ortotanásia é considerada pela literatura como a "morte digna”, a forma mais adequada, natural, correta e confortante de morte (sem sofrimento). Sem prolongamento interventivo obstinado (distanásia) e sem abreviação injusta ou ilegal (eutanásia). Sem postergá-la nem precipitá-la. É o não investimento em ações obcecadas, e fúteis, que visam adiar a morte de um indivíduo cuja doença de base insiste em avançar acarretando a falência progressiva das funções vitais (REIRIZ et al., 2006; PESSINI; BERTACHINI, 2004). Trata-se, portanto, de um conceito relacionado à paliatividade, o reverso da moeda, que focaliza na qualidade e não na duração da vida, na prestação de cuidado que não cura, porém oferece proteção digna ao sofrimento.

A fim de regulamentar os limites da ortotanásia no Brasil, o CFM editou, no ano de 2006, a Resolução n. 1.805/2006, que permite, por força de seu art. $1^{\circ}$, que o médico interrompa tratamentos e procedimentos que prolonguem a vida do doente em estado terminal, sem condições de reversibilidade (enfermidade grave e incurável), com sua declaração expressa de vontade, ou de seus familiares ou representante legal (CFM, 2006). A Resolução contém apenas três artigos e estabelece algumas regras para a interrupção: esclarecimento ao paciente ou a seu representante legal das modalidades terapêuticas adequadas para cada situação (art. $1^{\circ}, \S 1^{\circ}$ ), registro em prontuário médico (art. $1^{\circ}, \S 2 \circ$ ), possibilidade de doente ou representante solicitarem uma segunda opinião médica (art. $1^{\circ}, \S 3$ ) e manutenção de cuidados necessários para alívio de sintomas e conforto $\left(\right.$ art. $2^{\circ}$ ). Em sua exposição de motivos, a norma traz importantes ponderações acerca da fundamental busca pelo equilíbrio entre disponibilidade biotecnológica e suas relações éticas e morais com a dor, o sofrimento e o paradigma da cura médica.

Muito embora a Resolução tenha sido contestada via ajuizamento da Ação Civil Pública (ACP) no 2007.34.00.0149809-3, perante a 14 ${ }^{\text {a }}$ Vara Federal do Distrito Federal, tendo seus efeitos suspensos temporariamente por via de liminar, nas alegações finais proferidas em $1^{\circ}$ de dezembro de 2010 , o judiciário considerou que não há ilegitimidade na norma?.

Ao que indica o texto da referida resolução, o CFM pretendia evitar que pacientes fossem submetidos a condições de sofrimento físico, moral, psíquico ou social em razão de tentativas de manutenção da vida clínica ou biológica desenfreadas e desarrazoadas. Em tese, se buscou traduzir a máxima de que recurso técnico disponível em saúde não significa recurso obrigatoriamente a ser utilizado. Entretanto, a iniciativa,

\footnotetext{
${ }^{9}$ Disponível em: https://processual.trf1.jus.br/consultaProcessual/processo.php?secao=DF\& proc $=20$ 0734000148093.
} 
além de inicialmente refutada judicialmente, recebeu críticas de parte da academia, que considerou a possibilidade de desvirtuamento de sua finalidade e aplicação avessa, consistente na possibilidade de ocorrência de distorções de juízo de valor que culminassem com o não investimento terapêutico adequado em casos devidos.

Ultrapassada a discussão a respeito da legitimidade da Resolução, assegurada, ao final, pelo Judiciário, cumpre-nos apontar algumas das lacunas não suprimidas pela norma. $\mathrm{O}$ texto proferido pelo CFM, indiscutivelmente, falha ao não apontar caminhos para a concretude de seus dispositivos. Seus preceitos são absolutamente justificáveis, porém, incontroversamente genéricos. Em primeiro lugar, a Resolução não indicou qual seria o parâmetro para definição de "doente em fase terminal" e de "enfermidade grave e incurável", sequer esclareceu se isso seria estipulado a posteriori pelo Conselho de Classe, pela literatura médica, pelas próprias instituições de saúde ou pelo legislador. Em segundo lugar, nada precisou sobre a possibilidade de segunda opinião médica: o profissional a ser consultado seria pertencente a corpo clínico diverso ao da instituição de vinculação daquele que proferiu a primeira opinião? A garantia da oportunidade de segunda opinião é responsabilidade da instituição que emitiu a primeira apreciação ou está a cargo de familiares e pacientes? Não resta claro.

Seis anos mais tarde, em 2012, o CFM editou a Resolução n. 1.995/2012 (CFM, 2012), que dispõe sobre as diretivas antecipadas de vontade dos pacientes, definidas como o conjunto de desejos, prévia e expressamente, sobre cuidados e tratamentos que quer, ou não, receber no momento em que estiver incapacitado de expressar, livre e autonomamente, sua vontade $\left(\operatorname{art.} 1^{\circ}\right)$. Conquanto não trate especificamente sobre a terminalidade, possui relação direta e adstrita a ela.

Um pouco mais detalhada é verdade, a Resolução n. 1.995/2012 explica em que condições as diretivas serão utilizadas: pacientes incapazes de comunicar-se ou de expressar de maneira livre e independente suas vontades (art. $2^{\circ}$ ). A norma aduz, ainda, a possibilidade de designação de representante prévio (art. $2^{\circ}, \S 1^{\circ}$ ); a abstenção de acolhimento, por parte dos profissionais de saúde, de diretivas contrárias aos ditames do Código de Ética Médica (art. $2^{\circ}, \S 2^{\circ}$ ); a prevalência das diretivas sobre o desejo de

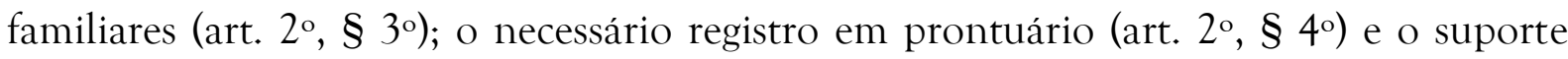
aos casos conflituosos pelo Comitê de Bioética, Comissão de Ética Médica da instituição e Conselho Regional e Federal de Medicina (art. 2º, § 5).

Apesar de se constituir, com efeito, em um progresso no sentido das garantias fundamentais do Estado Democrático de Direito, a Resolução possui inquestionáveis limitações. A regra disposta pelo CFM não prosperou no sentido de apontar quais seriam os caminhos trilhados para a implementação, de ordem prática, de suas disposições. Não determinou, por exemplo, qual o procedimento para certificar-se da existência de uma Diretiva Antecipada de Vontade (DAV) ou procuração de saúde, nem 
os critérios adotados para a qualificação de "representante legal", sobretudo em se tratando de pacientes maiores sem DAV, sem procurador nem curador previamente nomeado, por exemplo. Tampouco dispôs se haveria algum período de "carência", isto é, se o "expresso previamente" contemplaria manifestações exaradas após admissão nos serviços de saúde, formuladas já à beira do leito, por exemplo.

Assim como ocorrera com a Resolução n. 1.805/2006, o Ministério Público Federal contraditou o conteúdo da Resolução n. 1.995/2012, ajuizando a Ação Civil Pública de n. ${ }^{\circ}$ 1039-86.2013.4.01.3500 (BRASIL, 2013a) perante a Primeira Vara Federal da Seção Judiciária do Estado de Goiás, com o objetivo de declarar a inconstitucionalidade e a ilegalidade da norma, sob alegação de que ela extravasaria os limites do poder regulamentar, imporia riscos à segurança jurídica, alijaria a família de decisões que lhe são de direito e estabeleceria instrumento inidôneo para o registro de diretivas antecipadas. Em sede de sentença (BRASIL, 2013b), o juízo reconheceu que o Conselho Federal de Medicina não extrapolou sua competência legalmente estabelecida, tampouco agiu em contradição à Constituição Federal, reconhecendo pelo contrário, sua compatibilidade com a autonomia da vontade e o princípio da dignidade humana.

Por fim, têm-se a Resolução CFM n. 2.156/2016 (CFM, 2016), que estabelece os critérios de admissão e alta em unidade de terapia intensiva. A norma tangencia as questões atinentes à terminalidade e pode ser considerada vanguardista (nacionalmente) no sentido de estabelecer parâmetros técnicos mínimos para a prática médica nesse nicho de atuação.

Além de definir, em seu art. $1^{\circ}, 5^{\circ}$ e $10^{\circ}$, parâmetros objetivos para a tomada de decisão médica quanto à admissão do paciente em unidade de terapia intensiva (UTI), a normativa traz a necessidade de justificativa em prontuário para as solicitações de vaga dessa espécie $\left(\operatorname{art.} 3^{\circ}\right.$ ) e de comunicação à família ou ao representante legal (art. $4^{\circ}$ ). Indo adiante, a resolução trata da ordem de priorização clínica a ser adotada em cenários de recursos escassos ou limitados (art. $6^{\circ}$ ), da necessidade de garantia de não discriminação $\left(\right.$ ar. $9^{\circ}$ ) e do dever dos serviços de tratamento intensivo desenvolverem protocolos de conduta, com a correspondente publicização desses instrumentos ao corpo clínico e à direção técnica dos nosocômios e aos gestores do sistema de saúde (art. 11\%). A limitação mais evidente da aludida resolução diz respeito à amplitude e abrangência dos critérios de norteamento da tomada de decisão sobre o encaminhamento do doente para cuidados intensivos. Em verdade, a norma cita, em seu art. $1^{\circ}$, preceitos gerais, aplicáveis à quase totalidade das situações clínicas da prática médica, como por exemplo, o "diagnóstico" a "necessidade do paciente", o "potencial benefício para o paciente com as intervenções terapêuticas" e o "prognóstico". Note-se que não há um grau de detalhamento ou refinamento voltado à terminalidade ou à terapia intensiva propriamente ditas. Esse 
vácuo, do ponto de vista prático, acaba por esvaziar a aplicabilidade da norma no cotidiano médico.

Para além dos aspectos aqui mencionados, na dinâmica dos hospitais e das unidades de terapia intensiva exsurgem outros desafios quanto à aplicabilidade das aludidas resoluções. Quando transportados para as rotinas dos serviços de saúde, os obstáculos ao cumprimento das normas são de tal ordem que elas se fazem, por vezes, inexequíveis. No tópico seguinte abordaremos, de modo breve, alguns dos principais desafios para a práxis das Resoluções n. 1.805/06, n. 1.995/2012 e n. 2.156/2016 do Conselho Federal de Medicina.

\section{DESAFIOS PARA APLICABILIDADE DAS NORMAS DO CFM ACERCA DA TERMINALIDADE}

O paciente terminal é considerado o doente para quem a medicina não oferece nenhuma chance real de cura (GARCIA, 2007). A terminalidade, conforme afirma Sztajn (2009, p. 252), é estado de fato, estado da natureza, em que a superveniência da morte, seja por agravamento da doença, seja por outra causa (trauma ou acidente) é inevitável. Os tratamentos paliativos, voltados à terminalidade, também denominados cuidados tipo hospice ou extraordinários, portanto, são aqueles prestados ao enfermo cuja doença já não responde ao tratamento curativo.

Em linhas gerais, pode-se dizer que muitos são os desafios que obstam o bem cuidar do paciente em fase de paliatividade. De forma esquemática, esses fatores podem ser divididos em institucionais, estruturais, técnico-jurídicos e sociais. Eles compõem os principais entraves com os quais se deparam pacientes nessa condição. A seguir, discorremos sobre alguns dos mais elementares, conforme disposto na tabela 1:

Tabela 1 - Entraves à aplicabilidade das soft laws publicadas pelo Conselho Federal de Medicina acerca da terminalidade

\begin{tabular}{l|l}
\hline \multicolumn{1}{c|}{ Categoria } & Espécies \\
\hline i) Estruturais & a) $\begin{array}{l}\text { Dificuldades de acesso, pela precariedade ou total ausência do } \\
\text { sistema público de saúde em determinadas áreas geográficas e } \\
\text { espaços de saber médico; }\end{array}$ \\
b) Limitação de insumos, equipamentos e leitos; \\
c) Ausência de equipe multiprofissional adequada ao manejo dos \\
casos; \\
d) Grande número de decisões em caráter de urgência, fator que \\
dificulta a elaboração de conflitos de forma mais aprofundada.
\end{tabular}

14 - R. Opin. Jur., Fortaleza, ano 19, n. 30, p.1-34, jan./abr. 2021 


\begin{tabular}{|c|c|c|}
\hline & e) & Aspectos epidemiológicos da população; \\
\hline \multirow[t]{2}{*}{ ii) Institucionais } & a) & $\begin{array}{l}\text { Ausência de protocolos e rotinas de paliatividade em diversas } \\
\text { instituições de saúde; }\end{array}$ \\
\hline & b) & $\begin{array}{l}\text { Implementação de protocolos de paliatividade pró-forma } \\
\text { (demasiadamente genéricos e abstratos, com a consequente } \\
\text { dificuldade de sua aplicação). }\end{array}$ \\
\hline \multirow[t]{4}{*}{$\begin{array}{l}\text { iii) Técnico- } \\
\text { jurídicos }\end{array}$} & a) & $\begin{array}{l}\text { Incompletude e lacunas das normas soft laws, vez que não } \\
\text { trazem definições conceituais importantes ("doente em fase } \\
\text { terminal" e "enfermidade grave e incurável"); }\end{array}$ \\
\hline & b) & $\begin{array}{l}\text { Insuficiência de conhecimento técnico e normativo por parte } \\
\text { de profissionais da saúde; }\end{array}$ \\
\hline & c) & Falha na capacitação de equipes de saúde; \\
\hline & d) & $\begin{array}{l}\text { Ausência de fluxos para a utilização das diretivas antecipadas } \\
\text { (utilização acanhada das D.A). }\end{array}$ \\
\hline \multirow[t]{2}{*}{ iv) Sociais } & a) & $\begin{array}{l}\text { Temor de implicações ético legais por parte de profissionais de } \\
\text { saúde; }\end{array}$ \\
\hline & b) & Tabu filosófico e religioso que envolve a morte. \\
\hline
\end{tabular}

Fonte: elaborado pelas autoras (2020).

Nesse contexto, a Organização Mundial da Saúde concluiu que, em 1999, apenas $14 \%$ dos pacientes americanos que necessitavam de cuidados paliativos receberam esse tipo de atenção. Em 2006, o percentual passou para 33\% (KELLEY; MORRISON, 2015). Aqui se identifica um primeiro obstáculo que parece, também, ocorrer no Brasil: as limitações de acesso às práticas de paliatividade. Trata-se de fator enfrentado por pacientes e familiares que buscam os serviços de saúde, públicos e privados, e se veem aviltados ante o franco ou o sutil descumprimento das Resoluções CFM 1.805/06, CFM 1.995/2012 e CFM 2.156/2016. Isso porque nem todas as unidades de saúde do país que recebem doentes nessas condições possuem protocolos, diretrizes ou programas que estabeleçam parâmetros e critérios para os atendimentos. Ou seja, nem todos os serviços que lidam com a terminalidade traduziram as normas do Conselho de Classe de Medicina em instrumentos e rotinas práticas. Tanto assim que apenas em 31 de outubro de 2018, por via da Resolução n. 41 da Comissão Intergestores Tripartite ${ }^{10}$ do Sistema

${ }^{10}$ Disponível em: http://portalarquivos2.saude.gov.br/images/pdf/2018/novembro/23/RESOLUCAO -N41.pdf. 
Único de Saúde (SUS), foram inseridos cuidados paliativos nos serviços continuados integrados ofertados no âmbito da Rede de Atenção à Saúde (RAS) do sistema público. A Resolução definiu princípios norteadores para organização e oferta do cuidado em qualquer ponto da RAS: atenção básica, atenção domiciliar, atenção ambulatorial, urgência e emergência e atenção hospitalar. Passou a vigorar no momento da publicação, há pouco mais de um ano. Não se tem conhecimento de dados oficiais sobre sua repercussão, porém, na prática, o que se vê, é que muitas instituições permanecem desguarnecidas de qualquer organização formal quanto às condutas praticadas frente à paliatividade.

Em um estudo realizado em 2011, cerca de cinco anos após a emissão da Resolução n. 1.805/2006, entre 9,64\% (5 a 10 anos de formação) e 40,96\% ( $<5$ anos de formação) dos médicos entrevistados informaram que a norma não alterou seu cotidiano de atendimento (VASCONCELOS; IMAMURA; VILLAR, 2011). Uma das hipóteses a ser levantada para a interpretação do dado é justamente a não "tradução" da norma (ou a má "tradução") em diretrizes e protocolos que subsidiem a tomada de decisão clínica. Em estudo realizado no Distrito Federal, quanto às influências no processo de tomada de decisão em relação às decisões sobre a introdução ou não de suporte vital em pacientes terminais, ainda que o critério técnico tenha sido considerado relevante para embasar a deliberação dos médicos entrevistados, alguns profissionais mencionaram que motivações subjetivas e de foro íntimo seriam preponderantes para tais raciocínios (SANCHES; SEIDL, 2013). A instituição de protocolos oficiais, de rigor científico, por certo, possui potencial para minorar esses cenários.

Em outros casos, o que se tem é a adoção de protocolos de paliatividade de conteúdo abstrato e genérico - que até aludem aos preceitos da bioética -, porém não progridem do ponto de vista funcional, ou seja, não evidenciam, de fato, como pretendem alcançar os fundamentos de beneficência, não-maleficência, autonomia e justiça (BEAUCHAMP; CHILDRESS, 1994). Não enfrentam honestamente o debate e não problematizam as aflições práticas dos profissionais de saúde: i) parâmetros técnicos de irreversibilidade do quadro clínico; ii) procedimentos invasivos (definição e indicação); iii) (in) capacidade civil e consciência; iv) medidas específicas em paliatividade, considerando-se as principais entidades nosológicas; v) ações de stop de intervenção (extubação paliativa, diminuição/retirada de drogas vasoativas, diminuição/retirada de alimentação enteral, diminuição/retirada de sedação e ou hidratação, indicação de diálise); vi) suporte social e jurídico a pacientes e equipe de saúde. Há que se registrar que, em razão da maior proximidade com a temática, os protocolos oncológicos de paliatividade são os mais comumente utilizados e, talvez por isso, os mais difundidos e aperfeiçoados na prática médica (SILVA; HORTALE, 2006; MENDES; VASCONCELLOS, 2015). Mencione-se como exemplo o instrumento 
"Cuidados Paliativos Oncológicos - Controle de Sintomas" desenvolvido pelo Instituto Nacional do Câncer (INCA) ${ }^{11}$, baseado no guideline desenvolvido pela Organização Mundial da Saúde ${ }^{12}$. Para os demais grupos de doenças e especialidades médicas a inexistência ou a limitada qualidade dos instrumentos adotados parece ainda mais importante.

Outra adversidade encontrada para a aplicabilidade das regras promulgadas pelo CFM acerca da terminalidade diz respeito às estruturas dos serviços de saúde distribuídos pelo país. Nem todos dispõem do desejável suporte multidisciplinar para atuação nos casos de terminalidade. Não raro, a equipe responsável pelos atendimentos é formada apenas por médicos e profissionais da enfermagem. A ausência de assistentes sociais, psicólogos, nutricionistas, fisioterapeutas, terapeutas ocupacionais, fonoaudiólogos, assistente espiritual e juristas nos processos de terminalidade torna ainda mais custosa a tarefa de garantir os direitos fundamentais dos pacientes, acolher adequadamente os familiares e, ao mesmo tempo, adotar boas práticas médicas.

Além disso, em muitos nosocômios e instituições de saúde não há um fluxo claro sobre a utilização das diretivas antecipadas, do mandato duradouro ou da declaração prévia de vontade do paciente terminal (VITOR, 2004; NAVES, REZENDE, 2007; DADALTO, 2009). Não é rotina em grande parte dos estabelecimentos, por exemplo, solicitar esses documentos no momento da admissão. Em muitos casos, sequer há o cadastramento formal de representantes legais e de familiares que participam do processo de cuidado do paciente. Habitualmente, apenas um "responsável legal” assina o documento de internação do doente e, no mais das vezes, não há informação/regulamentação que defina qual familiar/acompanhante seria o mais apto a fazê-lo. Tampouco há convenções ou regramentos que esclareçam o modo como devem ser resolvidos os conflitos resultantes de opiniões divergentes entre familiares interferentes no tratamento. Em alguns países como Espanha e Dinamarca a legitimação das diretivas antecipadas se dá, de modo prático, via agrupamento das informações em cartão magnético de posse do paciente ou depósito do documento em base informatizada (BETANCOR, 1995).

O fato de muitas questões sobre a paliatividade e o fim da vida tratarem de situações que requerem tomada de decisão ágil e urgente também pode ser considerado um limitador para o bom atendimento às normativas do CFM. Em muitos casos, não há tempo hábil para os conflitos serem levados à apreciação do Comitê de Bioética ou à Comissão de Ética Médica da instituição, ao Conselho Regional ou Federal de Medicina, ao Ministério Público ou ao Judiciário. As tragédias acabam deliberadas nos limites estreitos do microambiente nosocomial e o julgamento é materializado ali

\footnotetext{
${ }^{11}$ Disponível em: http://www1.inca.gov.br/rbc/n_48/v02/pdf/condutas3.pdf.

${ }^{12}$ Disponivel em: https://apps.who.int/iris/handle/10665/42494.
} 
mesmo, em meio aos sons característicos das unidades de terapia intensiva, ao exame de consciência do médico e as manifestações dos membros das modernas composições familiares dos pacientes. Cumpre-nos salientar que, a despeito da eventual inexequibilidade prático-temporal de atuação nas decisões de urgência, os Comitês de Ética Médica e as Comissões de Bioética possuem papel fundamental nas condução do paciente terminal, seja para coordenar o debate e a produção de documentos institucionais, seja para desempenhar papel preventivo e pedagógico determinante.

Há, também, o fator desconhecimento da classe médica. Em estudo realizado em 2011 os autores observaram que cerca de 56\% dos 83 médicos participantes afirmaram desconhecer a Resolução n. 1.805 do CFM. Entre os conceitos de ortotanásia, distanásia e eutanásia, o de ortotanásia gerou maior confusão conceitual entre os participantes (VASCONCELOS; IMAMURA; VILLAR, 2011). Em pesquisa realizada com médicos oncologistas do Distrito Federal, concluiu-se que um terço dos participantes não conhecia a referida resolução (SANCHES; SEIDL, 2013). Outro manuscrito que investigou os efeitos da Resolução n. 1.805/06 em médicos que trabalhavam em unidade de terapia intensiva em São Paulo constatou que 49\% deles desconheciam a normativa (VANE; POSSO, 2011). Em levantamento realizado no Distrito Federal, que contou com a participação de quinze médicos intensivistas procedentes do estado de Goiás e do Distrito Federal, constatou-se que 40\% dos participantes desconheciam a Resolução 1.805/06 (BATISTA; SEIDL, 2011). Na ocasião em que médicos fizeram uma autoavaliação sobre o nível de conhecimento a respeito das vontades antecipadas, em uma escala entre 0 (muito ruim) e 10 (excelente), o score médio de conhecimentos foi de 5,88. Quando interrogados sobre se fariam a própria declaração de diretiva de vontade no futuro próximo, a maioria dos profissionais indicou que era pouco provável, com uma média de 4,17 , onde 0 significa pouco provável e 10 muito provável (STOLZ et al., 2011).

O temor das implicações ético legais, as falhas na capacitação, a insegurança para decidir e a falta de consenso entre a equipe de saúde são outros motivos aventados para a limitada aplicação da Resolução n. 1.805/2006 (BATISTA; SEIDL, 2011).

Para além desses fatores, há o tabu religioso filosófico que circunda a morte e as diretiva antecipadas. Tal como acontece com o testamento particular e os contratos de assistência funerária, há certo pavor generalizado em tratar, preventivamente, situações que envolvem a morte. Também por isso talvez não sejam tão comuns os casos de pacientes que internam já em posse de instrumentos de diretivas antecipadas ou de declaração prévia de vontade.

Pode-se mencionar, ainda, outras questões práticas que obstam o desejável atendimento às normativas do CFM relativas à terminalidade: aquelas relacionadas às limitações de ordem epidemiológica e social. Em razão de baixos investimentos em 
medicina preventiva na saúde pública (desfinanciamento), são comuns as internações de pacientes agudizados, descompensados em quadros de urgência/emergência, que sequer contavam com diagnóstico prévio e com acompanhamento adequado quanto às condições crônicas de saúde. Nesses casos, como há desconhecimento absoluto do estado de saúde pelo próprio paciente, algumas das alternativas para minoração dos conflitos no momento da terminalidade tornam-se pouco atrativas, como é o caso das diretivas antecipadas. Diante de uma suposta "higidez" o paciente se sente desestimulado para formalizar, antecipadamente, seus desejos para o momento da morte.

Outras questões que limitam a aplicabilidade das Resoluções CFM 1.805/06 e CFM 1.995/2012 são as lacunas deixadas pelas próprias normas. A definição sobre quais sujeitos podem fazer diretivas antecipadas (menores de 18 anos?), a especificação dos tratamentos que podem ser aceitos ou recusados no termo (proporcionalidade terapêutica, doação de órgãos), a obrigatoriedade do registro em cartório de notas e a criação do Registro Nacional de Diretivas Antecipadas, bem como o acompanhamento de um médico na feitura das diretivas são algumas das implicações jurídicas das Resoluções que restam duvidosas e carecem de regulamentação legal (DADALTO, 2013).

Enfim, o esforço do Conselho Federal de Medicina em trazer o assunto ao debate e formalizar, minimamente, regras para o contexto da terminalidade, é louvável. Inobstante, como é de se verificar, são múltiplas as dificuldades técnicas, éticas, jurídicas e sociais que limitam a aplicabilidade das normas. A seguir, abordaremos, de modo preambular, algumas possibilidades de enfrentamento de tais adversidades.

\section{APOSTA NAS BOAS PRÁTICAS PARA SUPERAÇÃO DOS OBSTÁCULOS}

Os obstáculos técnicos, éticos, jurídicos e sociais para a aplicabilidade do quanto preconizado pelo CFM em relação à paliatividade, por força das Resoluções $\mathrm{n}^{\text {* }}$ 1.805/2006, 1.995/2012 e 2.156/2016, são manifestos.

Do ponto de vista técnico, algumas iniciativas integrantes de um conjunto maior denominado de boas práticas médicas podem ser adotadas com o propósito de suplantálos ou minorá-los. O primeiro deles talvez seja o de evitar o reducionismo científico (SGRECCIA, 1996). Em outras palavras, importante ultrapassar as reflexões exclusivamente biomédicas sobre a terminalidade, expandindo-as para terrenos correlatos e multi-transdisciplinares, como o da sociologia, filosofia, assistência social, psicologia e direito. Abrir e ampliar o diálogo é um bom start para o adequado encaminhamento dos conflitos em paliatividade. 
Difundir nos ambientes acadêmicos e nos serviços de saúde os conteúdos das resoluções do CFM e apregoar o cuidado solidário, que une competência técnicocientífica e humanidade, principalmente em situações extremadas e fronteiriças entre a vida e a morte, também consiste em importante medida para dissolução de embates (BETTINELLI; WASKIEVICZ; ERDMAN, 2004).

Indo além, assinalamos outras medidas que apresentam potencial para o alcance do objetivo de melhor compreensão e adoção das resoluções do CFM atinentes à terminalidade:

\subsection{INSTITUIÇÃO DE PROTOCOLOS, DIRETRIZES, ROTINAS, PROCEDIMENTOS OPERACIONAIS PADRÃO E/OU PROGRAMAS DE CUIDADOS PALIATIVOS NAS INSTITUIÇÕES QUE PRESTEM ATENDIMENTO A PACIENTES NESSA CONDIÇÃO}

Idealmente, protocolos técnicos ou congêneres devem ser implementados em todas as unidades de saúde, públicas ou privadas, que lidam diretamente com o evento morte (unidade básicas, pronto atendimentos, pronto socorros, enfermarias, unidades de terapia intensiva e semi-intensiva), com obediência aos princípios éticos da medicina paliativa:

a) veracidade: fundamento nas relações entre médicos, pacientes e familiares;

b) proporcionalidade terapêutica: relação proporcional entre os meios terapêuticos empregados e os resultados esperados - riscos e benefícios da ação ou omissão;

c) duplo efeito: todo ato terapêutico possui um efeito positivo e outro negativo;

d) prevenção: agir para evitar possíveis complicações inerentes à evolução clínica;

e) não abandono e tratamento da dor: não deserção de paciente em razão de ele recusar-se a se submeter a determinado tipo de terapia que o médico julgou ser a mais adequada e tratamento álgico satisfatório (TABOADA, 2000).

Um bom exemplo da apropriada instituição de protocolo de terminalidade é a diretriz para cuidados paliativos em pacientes críticos admitidos em UTI elaborada pela Gerência de Serviços de Terapia Intensiva da Secretaria de Estado da Saúde do Distrito Federal, publicada pela Portaria SES-DF no 418, de 04 de maio de $2018^{13}$. O documento, além de oficialmente formalizado, possui princípios bem definidos; apresenta conceitos básicos e aspectos jurídicos sobre a terminalidade; contém critérios

\footnotetext{
${ }^{13}$ Disponivel em: http://www.saude.df.gov.br/wp-conteudo/uploads/2018/04/3.-Diretrizes-paraCuidados-Paliativos.pdf.
}

20 - R. Opin. Jur., Fortaleza, ano 19, n. 30, p.1-34, jan./abr. 2021 
de inclusão e exclusão; define indicadores clínicos de monitoramento; fundamenta a tomada de decisão em escalas/scores validados cientificamente; dispõe de fluxogramas de avaliação, discussão, conduta e intervenção; sugere roteiro para uma boa comunicação; apresenta noções detalhadas sobre o controle de sintomas; discute a sedação; aborda o acompanhamento pós-alta e estabelece mecanismos de controle e prestação de contas.

Vale registrar que a disponibilidade de um serviço de cuidados paliativos é, atualmente, critério para acreditação adotado pela American College of Surgeons Commission on Cancer, além de ser utilizada para a definição dos melhores centros médicos dos Estados Unidos (COELHO; YANKASKAS, 2017). Esse é um indicativo do nível de amadurecimento que o debate apresenta na comunidade internacional e do grau de importância que essa modalidade de serviço representa.

\subsection{UTILIZAÇÃO DE INDICADORES CLÍNICOS OBJETIVOS E MENSURÁVEIS PARA CARACTERIZAÇÃO DE ESTADO DE TERMINALIDADE}

Alguns indicadores potencialmente utilizáveis para a caracterização do estado de terminalidade, a depender do nicho de especialidade clínica e do perfil dos doentes admitidos, são: i) desempenho funcional em declínio e deteriorado: autocuidado limitado, restrito ao leito ou poltrona em mais de 50\% do tempo e aumento da dependência para a maioria das atividades da vida diária (higiene, alimentação, mobilidade); ii) presença de comorbidades de alta letalidade; iii) derrocada física global: perda progressiva de massa e força muscular, caquexia; iv) dificuldade progressiva para comunicar-se; v) doença avançada: instabilidade hemodinâmica e sintomas severos; vi) hipo ou aresponsividade ao tratamento; vii) inviabilidade clínica para tratamentos invasivos; viii) perda de peso progressiva e importante: > 10\% nos últimos seis meses; ix) repetidas internações não eletivas; $\mathbf{x}$ ) presença de evento sentinela: quedas, luto, transferência para instituição de longa permanência; xi) albumina sérica $<2,5 \mathrm{~g} / \mathrm{dL}$; xii) sintomas refratários a despeito de tratamento específico otimizado; xiii) dispneia ou angina em repouso; xiv) disfagia progressiva; xv) indicadores clínicos de gravidade e progressão específicos (neoplasias metastáticas, doença pulmonar obstrutiva crônica, cardiopatia crônica, doenças cerebrovasculares, insuficiência renal crônica, doença hepática crônica, demência) (SANTOS et al., 2017). Para além desses, podem ser mencionados: anorexia persistente; imobilidade; sonolência persistente (na ausência de sedação induzida); alterações progressivas de cognição e delirium; mioclonus (abalos musculares involuntários); palidez cutânea, extremidades frias, pele marmórea e cianose periférica; respiração ruidosa (ruído/ronco da morte ou sororoca). 


\subsection{UTILIZAÇÃO DE ESCALAS INSTRUMENTAIS PADRONIZADAS E VALIDADAS CIENTIFICAMENTE PARA DEFINIÇÃO DE PROGNÓSTICO DE PACIENTES EM SITUAÇÃO DE PALIATIVIDADE}

As principais ferramentas reconhecidas internacionalmente úteis para fins de definição diagnóstica e prognóstica em paliatividade são: a) Palliative Performance Scale - PPS (ANDERSON, 1995); b) Escala de avaliação de sintomas ESAS; c) Escala de Atividades Básicas de Vida Diária - Katz (KATZ, 1963); d) Protocolo de Identificação do Idoso Vulnerável - Vulnerable Elders Survey - VES 13 (SALIBA, 2003); e) APACHE II - Acute Physiology and Chronic Health Evaluation (KNAUS; DROPER; WAGNER, 1985); f) Sepsis-related Organ Failure Assessment SOFA - (MINNE; ABU-HANNA; JORGE, 2008); g) Simplified Acute Physiology Score - SAPS (METNITZ et al., 2005); h) Mortality Probability Model - MPM (HIGGINS, 2005).

\subsection{PREVISÃO DE AÇÕES GLOBAIS QUE CONTEMPLEM TODA LINHA DE CUIDADO DA TERMINALIDADE}

A atenção aos cuidados paliativos deve estar disponível a pacientes e familiares durante todo o itinerário percorrido no processo patológico ameaçador à continuidade da vida, inclusive no transcurso do luto. Independentemente se o paciente esteja alojado em nosocômio (emergência, enfermaria ou terapia intensiva), em seu domicílio (ambulatório, consultório ou hospital dia), em instituições de longa permanência ou em unidades de cuidados paliativos especializadas (hospice). O gráfico a seguir demonstra com clareza o percurso entre o diagnóstico de situação ameaçadora da vida e o óbito e sua relação com as ações paliativas.

Figura 1 - Representação ilustrativa das ações paliativas relacionadas ao prognóstico da doença até o momento pós óbito

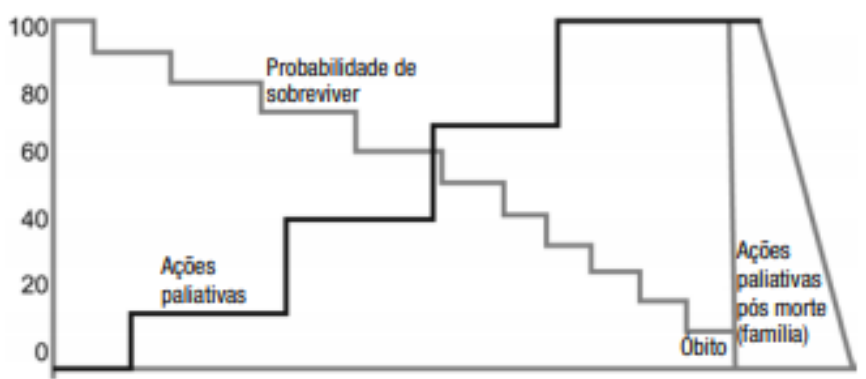

Fonte: (PIVA; GARCIA; LAGO, 2011). 


\subsection{FORMALIZAÇÃO DE TERMO PARA INCLUSÃO DO PACIENTE EM PROTOCOLO DE PALIATIVIDADE}

Importante a adoção de instrumento (termo) que formalize a vinculação do paciente ao protocolo de paliatividade, indicando, de maneira clara, quais critérios clínicos, laboratoriais e de imagem ensejaram a inclusão. Isso torna o processo mais transparente e seguro para o enfermo, para seus familiares e para os profissionais de saúde assistentes, além de permitir eventual auditagem pela Comissão de Revisão de Prontuários da instituição. $\mathrm{O}$ documento deve ser chancelado pelos pares envolvidos: médico, assistente social, psicólogo, paciente (caso haja condições clínicas), representante legal ou legítimo e, eventualmente, representante jurídico do estabelecimento hospitalar, a depender do grau de sua participação no processo e das peculiaridades do caso concreto, tais como a estrutura e a maturidade institucional. A finalidade da assinatura desse último seria a de garantir um olhar externo ao da equipe terapêutica e a preservação dos direitos fundamentais dos pacientes.

\subsection{ESTABELECIMENTO DE REGRAS SOBRE A DEFINIÇÃO DA PESSOA RESPONSÁVEL POR DECIDIR PELO PACIENTE EM CASO DE IMPOSSIBILIDADE DE MANIFESTAÇÃO DIRETA DE SUA VONTADE (ESTADO DE INCONSCIÊNCIA E CONGÊNERES)}

Muitas vezes, em meio a uma situação delicada de terminalidade, familiares disputam a posição de representante legítimo para decidir em nome do paciente, seja utilizando estratégias de persuasão e coação da equipe de saúde, seja buscando respaldo jurídico para tanto. Em ambos os casos, o resultado final acaba sendo o tumulto no interior do ambiente hospitalar. A fim de evitar esse tipo de situação e definir qual pessoa tem preferência ou prioridade para decidir em nome do paciente inconsciente, é fundamental a fixação de regras institucionais - apoiadas pelo Comitê de Bioética Hospitalar, Comissão de Ética Médica e considerados os parâmetros e limites jurídicos (LIMA; REGO; SIQUEIRA-BATISTA, 2015).

Do ponto de vista jurídico, o caminho proposto é a identificação do verdadeiro representante legal de fato e de direito previamente designado. Esse instituto é regulado basicamente pelo Código Civil (CC), pelo Código de Processo Civil (CPC) e pela Lei $n^{\circ}$ 13.143/2015, também conhecida como Estatuto da Pessoa com Deficiência (EPD) ${ }^{14}$.

${ }^{14}$ O EPD decorre da Convenção sobre os Direitos da Pessoa com Deficiência (2007), aprovada no Brasil por meio do Decreto legislativo n. 186/2008, conforme o procedimento do $\$ 3^{\circ}$ do art. $5^{\circ}$ da Constituição, portanto com status de norma constitucional. Em seguida, ela foi promulgada pelo Decreto n. 6.949/2009. Destinada a regular direitos das pessoas com deficiências, a lei assim as define: "aquela que tem impedimento de longo prazo de natureza física, mental, intelectual ou R. Opin. Jur., Fortaleza, ano 19, n. 30, p.1-34, jan./abr. $2021 \bullet 23$ 
Como regra, a correta identificação do representante legal passa pela busca de uma dentre as seguintes figuras: i) o curador nomeado judicialmente, nos termos dos art. 1.767 e seguintes do CC; ii) o apoiador nomeado judicialmente mediante pedido de Tomada de Decisão Apoiada, nos termos dos art. 1.783-A e seguintes do CC e do EPD; iii) o procurador para cuidados de saúde indicado pelo próprio paciente por meio de procuração com poderes específicos ou em Diretivas Antecipadas de Vontade (DAV), nos termos da Resolução 1.995/2012 do CFM.

Algumas ressalvas, contudo, são importantes. O EPD alterou radicalmente o sistema das incapacidades no Direito brasileiro e os contornos legais da curatela e, portanto, do representante legal por essa via designado. Com o intuito de humanizar esse processo e impedir que o curador invadisse as esferas mais íntimas do curatelado, o EPD (art. 85) determinou que a curatela afetaria "tão somente os atos relacionados aos direitos de natureza patrimonial e negocial”. Isso exclui, em princípio, as decisões na área da saúde, de natureza existencial e não patrimonial ou negocial, do âmbito de representação do curador. Aliás, é o que diz o parágrafo $1^{\circ}$ do mesmo artigo: "a curatela não alcança o direito ao próprio corpo, à sexualidade, ao matrimônio, à privacidade, à educação, à saúde, ao trabalho e ao voto" ${ }^{15}$. Na prática, algumas sentenças judiciais têm incluído esse poder ao curador/representante legal na área da saúde, mas de maneira extraordinária, ou seja, à pedido do curador e desde que demonstrada a severa condição de saúde que impossibilitasse a manifestação da vontade do doente. Isso nos leva à conclusão de que inclusive o curador, judicialmente nomeado, pode ter sua legitimidade questionada para tomada de decisões no campo da saúde.

No que se refere ao apoiador nomeado judicialmente mediante pedido de Tomada de Decisão Apoiada, cumpre registrar que se trata de instituto completamente novo no sistema jurídico brasileiro, incorporado em 2015 pelo EPD e, portanto, ainda pouco conhecido e utilizado. Até porque a lei exige processo judicial, sendo por vezes confundida com a curatela. Ambas devem ser aplicadas como medidas protetivas, sendo a curatela mais extraordinária e a TDA uma solução intermediária (entre a curatela e a procuração de saúde), por meio da qual a própria pessoa solicita ao juiz que nomeie duas outras pessoas idôneas e por ela escolhidas, em função dos vínculos de confiança, para apoiá-la na tomada de decisões para os atos da vida civil. Por medida protetiva, nesses casos, entenda-se aquela que respeite os direitos, a vontade e as preferências da

sensorial, o qual, em interação com uma ou mais barreiras, pode obstruir sua participação plena e efetiva na sociedade em igualdade de condições com as demais pessoas" (art. 2०). Além disso, em capítulo específico sobre o direito à vida (art. 10-13), o EPD trata do consentimento na área da saúde (medicina e pesquisa). Apesar de diversas inovações e melhorias, fato é que a referida lei não apresenta regulação precisa e específica para pacientes incapazes de manifestar sua vontade, como aqueles em estado de inconsciência, seja ele temporário ou permanente, de longo ou curto prazo.

${ }_{15}$ Para saber mais sobre o EPD, ver: Menezes, Pimentel e Lins (2020). 
pessoa, com isenção e sem conflito de interesses e de influência indevida, proporcional e apropriada às circunstâncias da pessoa, e aplicada pelo período mais curto possível e com revisão regular por uma autoridade ou órgão judiciário competente, independente e imparcial

Quanto ao procurador para cuidados de saúde, cumpre registrar que não há hoje lei específica sobre isso no Brasil. $O$ instituto do mandato mediante procuração, no entanto, é aceito e a ele aplica-se a legislação existente no CC, mais especificamente o art. 104. Como consequência, no ato de nomeação do procurador exige-se que o paciente tenha plena capacidade. Por outro lado, não há forma exigida ou predeterminada pela lei, podendo ser feito por meio de instrumento público ou simples declaração particular.

A pergunta que persiste é: e na ausência dessas figuras (representante legal), estabelecidas prévia e formalmente pela via judicial ou extrajudicial, quais princípios a equipe médica e/ou demais instâncias hospitalares poderiam adotar para definir a pessoa que irá decidir em nome do paciente? Visando a estabelecer critérios mais objetivos, uma alternativa é que esse processo de escolha utilize os mesmos parâmetros legais para a nomeação do curador, apoiador ou procurador. Assim, nos termos do art. 1.775 do CC, por exemplo, o cônjuge (i) teria prioridade em relação aos demais parentes para decidir em nome do paciente. Na falta do cônjuge, os pais (ii) e, na falta destes, os descendentes (iii) mais aptos, sendo que dentre eles os mais próximos precedem os mais remotos. O CC também autoriza a nomeação de mais de uma pessoa (art. 1.775-A do CC). Cumpre ressaltar, contudo, que do ponto de vista estritamente jurídico essa escolha pela equipe médica não fornece a mesma segurança. Por outro lado, o uso dos mesmos parâmetros legais pode auxiliar a padronizar esse processo de escolha do representante e ainda evitar uma futura judicialização.

No contraponto, sobreleva notar que, nem sempre, representantes legais possuem aptidão e/ou desejo de responder pelo melhor interesse de saúde do paciente representado. Enfim, a melhor compreensão das variáveis que compõem o processo de autorização por representação e sua complexidade (RAYMUNDO; GOLDIM, 2007), bem como sua padronização mínima (KIM et al., 2004), contribuem para tornar mais adequado o manejo dessas situações.

\subsection{REGISTRO EM ATA DE REUNIÕES COM FAMILIARES}

Outra medida também recomendada pela literatura diz respeito a eficaz e salutar comunicação entre a equipe de saúde, os pacientes e seus familiares nas situações envolvendo a terminalidade (COELHO; YANKASKAS, 2017). Nesse sentido, algumas precauções parecem importantes: definição expressa dos profissionais responsáveis pelo contato, cadastramento de familiares que prestam cuidado ao paciente e registro, em R. Opin. Jur., Fortaleza, ano 19, n. 30, p.1-34, jan./abr. $2021 \bullet 25$ 
prontuário médico ou ata anexa, de conversas e reuniões entre a equipe de saúde e os familiares/representantes. Há que se ressaltar que essa congregação, de fundamental importância para os encaminhamentos e desfechos dos casos, deve envolver, tanto quanto possível, a presença de profissionais da assistência social e da psicologia para suporte e mediação.

\section{CONCLUSÃO}

A morte assistida, enfrentada cotidianamente nos sistemas e serviços de saúde, a despeito de sua inexorabilidade, segue a desolar, sob diferentes aspectos, pacientes e profissionais responsáveis pelo cuidado. Poucos passam incólumes ao vivenciá-la à beira do leito. Nas últimas décadas, a revolução biotecnológica potencializou o principal dilema enfrentado pela prática médica nas situações de terminalidade: qual o ponto de equilíbrio entre intervenção reconfortante e obstinação terapêutica ultrajante? É uma questão de difícil resposta.

No intuito de aclarar esse tipo de dúvida a ordem jurídica e os órgãos representativos da sociedade têm buscado formas de regulamentar a matéria e mitigar as disputas. Entre as normativas formuladas, debruçamo-nos sobre as principais softlaw concernentes à Bioética e particularmente à terminalidade, vigentes no país: as Resoluções n. 1.805/06, n. 1.995/2012 e n. 2.156/2016 do Conselho Federal de Medicina. A primeira trata da interrupção de tratamentos e procedimentos que prolonguem a vida do doente em estado terminal, sem condições de reversibilidade e, a segunda, versa sobre as diretivas antecipadas de vontade.

No presente paper, reconhecemos o laudável esforço do Órgão de Classe em trazer o objeto ao debate. Todavia, ponderamos sobre as barreiras éticas, sociais, filosóficas, jurídicas e técnicas para a consolidação das normas no cenário brasileiro. Fornecendo alguns dados empíricos, sustentamos a tese de que há entraves que obstam a desejável aplicabilidade prática das referidas resoluções, entre as quais, apontamos os de natureza: i) estrutural: i.a) dificuldades de acesso, pela precariedade ou total ausência do sistema público de saúde em determinadas áreas geográficas e espaços de saber médico; i.b) limitação de insumos, equipamentos e leitos; i.c) ausência de equipe multiprofissional adequada ao manejo dos casos; i.d) aspectos epidemiológicos da população; i.e) grande número de decisões em caráter de urgência, fator que dificulta a elaboração de conflitos de forma mais aprofundada; ii) institucional: ii.a) ausência de protocolos e rotinas de paliatividade em diversas instituições de saúde; ii.b) implementação de protocolos de paliatividade pró-forma (demasiadamente genéricos e abstratos, com a consequente dificuldade de sua aplicação); iii) técnico-jurídica: iii.a) incompletude e lacunas das normas soft laws, vez que não trazem definições conceituais 
importantes ("doente em fase terminal" e "enfermidade grave e incurável"); iii.b) insuficiência de conhecimento técnico e normativo por parte de profissionais da saúde; iii.c) falha na capacitação de equipes de saúde; iii.d) ausência de fluxos para a utilização das diretivas antecipadas (utilização acanhada das D.A) e iv) social: iv.a) temor de implicações ético legais por parte de profissionais de saúde; iv.b) tabu filosófico e religioso que envolve a morte.

Diante dos entraves identificados, as autoras propõem algumas medidas com o intuito de superar os conflitos que impedem uma implantação mais expressiva das Resoluções: a) instituição de protocolos de paliatividade na totalidade dos serviços de saúde que recebem pacientes nessas condições; b) utilização de indicadores clínicos objetivos para fins de caracterização do estado de terminalidade; c) utilização de escalas e scores validados cientificamente para definição de prognóstico; d) previsão de ações globais que contemplem toda linha de cuidado da terminalidade; e) formalização de termo para inclusão de paciente em protocolo de paliatividade; f) estabelecimento de regras sobre a definição do responsável por decidir pelo paciente em caso de impossibilidade de manifestação direta se sua vontade (estado de inconsciência e congêneres); g) registro em ata de reuniões realizadas com familiares. Muitos deles já vem sendo adotados, de forma isolada ou coordenada, em alguns nosocômios, o que as autoras sugerem é a condensação e consolidação dessas práticas em todos os serviços públicos e privados de saúde que recebam pacientes em estágio terminal, como forma de fomentar a observância às softlaws referentes à terminalidade publicadas pelo Conselho Federal de Medicina.

Por fim, é de se dizer, nas palavras de Nunes (2008), que maiores possibilidades técnicas de intervenção sobre os pacientes devem exigir maior responsabilidade por parte dos cientistas e dos profissionais e maior necessidade de orientação ética na ação. $\mathrm{Na}$ verdade, e por princípio, não existem limites éticos à ciência, em si mesma. Mas tãosomente à sua utilização. A dificuldade parece consistir, justamente, em alcançar essa baliza, zelando pelos preceitos éticos, morais, filosóficos, religiosos, sociais, técnicos e jurídicos em cada caso concreto de terminalidade que aporta nos serviços de saúde.

\section{REFERÊNCIAS}

ANDERSON, Fern et al. Palliative performance scale (PPS): a new tool. Journal of

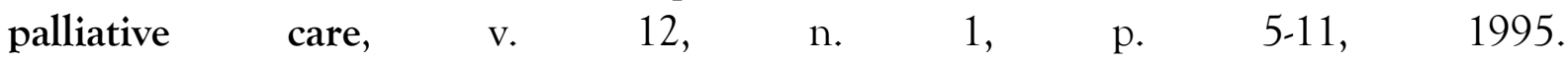
https://doi.org/10.1177/082585979601200102.

ANDORNO, Roberto. The invaluable role of soft law in the development of universal norms in bioethics, in: Workshop Die Umsetzung bioethischer Prinzipien im internationalen Vergleich, jointly organized by the. German Foreign Affairs Ministry 
and the German UNESCO Commission, Berlin, 2007. Disponível em: http://www.unesco.de/1507.html?\&L=0. Acesso em: 7 maio 2020.

BATISTA, Kátia Torres; SEIDL, Eliane Maria Fleury. Estudo acerca de decisões éticas na terminalidade da vida em unidade de terapia intensiva. Com. Ciências Saúde, v. 22, n. $1, \quad$ p. 51-60, 2011. Disponível em: https://bvsms.saude.gov.br/bvs/periodicos/revista_ESCS_v22_n1_a08_estudo_acerca_ decisoes_eticas.pdf. Acesso em: 7 maio 2020.

BEAUCHAMP, Tom Lamar; CHILDRESS, James Franklin. Principles of biomedical ethics. New York: Oxford; 1994. https://doi.org/10.1142/9781786340481_0004.

BETANCOR, Juana Teresa. Testamento vital. Eguzkilore. Cuaderno del Instituto Vasco de Criminologia, n. 9. 1995. Disponível em: https://www.ehu.eus/documents/ 1736829/2170448/10+_+El+testamento+vital.pdf. Acesso em: 7 maio 2020.

BETTINELLI, Luiz Antônio; WASKIEVICZ Josemara; ERDMAN, Alacoque Lorenzini. Humanização do cuidado no ambiente hospitalar. In: PESSINI L; BERTACHINI L. (ed.). Humanização e cuidados paliativos. São Paulo: Loyola, 2004. p. 87-100.

BRASIL. Ministério Público Federal. Petição inicial da ação civil pública n. 1039. 86.2013.4.01.3500. Goiás: MPF, 2013a. Disponível em: http://testamentovital.com.br/wp-content/uploads/2014/07/inicial-ACP-testamentovital.pdf. Acesso em: 7 maio 2020.

BRASIL. Poder Judiciário. Sentença da ação civil pública n. 1039-86.2013.4.01.3500. Goiás: MPF, 2013b. Disponível em: https://testamentovital.com.br/wpcontent/uploads/2018/05/senten\%C3\%A7a-ACP-testamento-vital.pdf. Acesso em: 7 maio 2020.

CAMPBELL, Angela; GLASS, Kathleen Cranley. The Legal Status of Clinical and Ethics Policies, Codes, and Guidelines in Medical Practice and Research. McGill Law Journal/ Revue de droitde McGill, v. 46, 2001. Disponível em: https://lawjournal.mcgill.ca/wp-content/uploads/pdf/6546121-Campbell_and_Glass. pdf. Acesso em: 7 maio 2020.

CARVALHO, Paulo Roberto Antonacci et al. Modos de morrer na UTI pediátrica de um hospital terciário. Rev Assoc Méd Brás, v. 47, n. 4, p. 325-31, 2001. https://doi.org/10.1590/s0104-42302001000400035.

COELHO, Cristina Bueno Terzi; YANKASKAS, James R. Novos conceitos em cuidados paliativos na unidade de terapia intensiva. Rev Bras Ter Intensiva, v. 29, n. 2, p. 222 230, 2017. Disponível em: https://www.scielo.br/pdf/rbti/v29n2/0103-507X-rbti-2902-0222.pdf Acesso em: 7 maio 2020. 
CONSELHO FEDERAL DE MEDICINA (CFM). Resolução n. 1.805/2006. Disponível em: http://www.portalmedico.org.br/resolucoes/cfm/2006/1805_2006. htm. Acesso em: 30 nov. 2019.

CONSELHO FEDERAL DE MEDICINA (CFM). Resolução 1.826/2007. Na fase terminal de enfermidades graves e incuráveis é permitido ao médico limitar ou suspender procedimentos e tratamentos que prolonguem a vida do doente [...]. 2007. Disponível em: https://sistemas.cfm.org.br/normas/visualizar/resolucoes/BR/2007/ 1826. Acesso em: 7 maio 2020.

CONSELHO FEDERAL DE MEDICINA (CFM). Resolução n. 1.995/2012. Dispõe sobre as diretivas antecipadas de vontade dos pacientes. Disponível em: https://sistemas.cfm.org.br/normas/visualizar/resolucoes/BR/2012/1995. Acesso em: 30 nov. 2019.

CONSELHO FEDERAL DE MEDICINA (CFM). Resolução n. 2.156/2016. Estabelece os critérios de admissão e alta em unidadede terapia intensiva. Disponível em: https://sistemas.cfm.org.br/normas/visualizar/resolucoes/BR/2016/2156. Acesso em: 4 maio 2020.

CONSELHO FEDERAL DE MEDICINA (CFM). Resolução 2.173/2017. Define os critérios do diagnóstico de morte encefálica. Disponível em: https://sistemas.cfm.org.br/normas/visualizar/resolucoes/BR/2017/2173. Acesso em: 7 maio de 2020.

DADALTO, Luciana. Declaração prévia de vontade do paciente terminal. Revista Bioética, v. 17, n. 3, p. 523-543, 2009. Disponível em: http://www.revistabioetica.cfm.org.br/index.php/revista_bioetica/article/viewFile/515 /516. Acesso em: 4 maio 2020.

DADALTO, Luciana. Morte digna para quem? O direito fundamental de escolha do próprio fim. Pensar Revista de Ciências Jurídicas, v. 24, n. 3, p. 1-11, 2019. https://doi.org/10.5020/2317-2150.2018.9555.

DADALTO, Luciana. Reflexos jurídicos da Resolução CFM 1.995/12. Revista Bioética, v. 21, n. 1, p. 106-12, 2013. https://doi.org/10.1590/s1983-80422013000100012.

FERREIRA, Sidnei. A mistanásia como prática usual dos governos. Jornal do Cremerj. Coluna do conselheiro, n. 324, p. 5, 2019. Disponível: http://www.cremerj.org.br/jornais/download/235. Acesso em: 21 ago. 2020.

FRAGA, Fabiana; VILAS BOAS, Rafaela Fernanda Oliveira Vilas; MENDONÇA, Adriana Rodrigues dos Anjos. Significado, para os médicos, da terminalidade da vida e 
dos cuidados paliativos. Rev Bioét, v. 20, n. 3, p.514-519, 2012. Disponível em: http://revistabioetica.cfm.org.br/index.php/revista_bioetica/article/view/773. Acesso em: 4 maio 2020.

GARCIA, Iberê Anselmo. Aspectos médicos e jurídicos da eutanásia. Revista Brasileira de Ciências Criminais, v. 15, n. 67, p. 253-275, 2007.

GODINHO, Adriano Marteleto. Ortotanásia e Cuidados Paliativos: O correto exercício da prática médica no fim da vida. In: GODINHO, A. M; LEITE, G. S; DADALTO, L. (coord.). Tratado Brasileiro Sobre Direito Fundamental À Morte Digna. São Paulo: Almedina Brasil, 2017.

GUIDELINES for the determination of death. Report of the medical consultants on the diagnosis of death to the President's Commission for the Study of Ethical Problems in Medicine and Biomedical and Behavioral Research. JAMA, n. 246, p. 2184-2186, 1981. https://doi.org/10.1001/jama.246.19.2184.

GUZMAN, Andrew T.; MEYER, Timothy L. International Soft Law. Spring, v. 2, n. 1, 2011. Disponível em: http://papers.ssrn.com/sol3/papers.cfm?abstract_id=1353444. Acesso em: 7 maio 2020.

HIGGINS, Thomas et al. Updated Mortality Probability Model - MPM0-III. Chest $\begin{array}{lllllll}\text { Journal. } & \text { v. } 128, & \text { n. } & 4, & \text { p. } & 348, & \end{array}$ https://doi.org/10.1378/chest.128.4_meetingabstracts.349s.

JUNGES José Roque et al. Reflexões legais e éticas sobre o final da vida: uma discussão sobre a ortotanásia. Rev Bioet, n. 18, v. 2, p. 275-288, 2010. Disponível em: https://www.researchgate.net/publication/277096033_Reflexoes_legais_e_eticas_sobre _o_final_da_vida_uma_discussao_sobre_a_ortotanasia. Acesso em: 21 ago. 2020.

KATZ, Sidney et al. Studies of illness in the aged. The index of ADL: a standardized measure of biological and psychosocial function. JAMA, v. 185, p. 914-919,1963. Disponivel em: https://www.ncbi.nlm.nih.gov/pubmed/14044222. Acesso em: 7 maio 2020.

KELlEY, Amy S.; MORRISON, R Sean. Palliative care for the seriously ill. N Engl J Med, v. 373, n. 8, p. 747-755, 2015. Disponível em: https://www.ncbi.nlm.nih.gov/pubmed/26287850. Acesso em: 7 maio 2020.

KIM, Scott et al. Proxy and surrogate consent in geriatric neuropsychiatric research: update and recommendations. Am J Psychiatry, v. 161, n. 5, p. 777-779, 2004. https://doi.org/10.1176/appi.ajp.161.5.797 . 
KNAUS William et al. APACHE II: a severity of disease classification system. Crit Care Med, v. 13, n. 10, p. 18-29, 1985. https://doi.org/10.1097/00003246-19860800000027.

LIMA, Maria de Lourdes Feitosa; REGO, Sérgio Tavares de Almeida; SIQUEIRABATISTA, Rodrigo. Processo de tomada de decisão nos cuidados de fim de vida. Rev. Bioét, v. 23, n. 1, p. 31-39, 2015. https://doi.org/10.1590/1983-80422015231043.

MAZZUOLI, Valério de O. Curso de direito internacional publico. 4. ed. São Paulo: Editora Revista dos Tribunais, 2010.

MENDES; Ernani Costa; VASCONCELLOS, Luiz Carlos Fadel. Cuidados paliativos no câncer e os princípios doutrinários do SUS. Saúde em Debate, v. 39, n. 106, p. 881892, 2015. https://doi.org/10.1590/0103-1104201510600030026.

MENEZES, Joyceane Bezerra; PIMENTEL, Ana Beatriz Lima; LINS, Ana Paola de Castro. A capacidade jurídica da pessoa com deficiência após a Convenção sobre os Direitos das Pessoas com Deficiência: análise das soluções propostas no Brasil, em Portugal e no Peru. Revista Direito $\&$ Práxis, 2020. Ahead of Print. Disponível em: https://www.e-publicacoes.uerj.br/index.php/revistaceaju/article/view/43240/33339. Acesso em: 21 ago. 2020. https://doi.org/ 10.1590/2179-8966/2020/43240.

METNITZ, Philipp et al. SAPS 3 Investigators. SAPS 3 - From evaluation of the patient to evaluation of the intensive care unit. Part 1: Objectives, methods and cohort description. Intensive Care Med, v. 31, n. 10, p. 1336-1344, 2005. https://doi.org/10.1007/s00134-005-2762-6.

MINNE, Lilian; ABU-HANNA, Amen; JORGE, Evert de. Evaluation of SOFA-based models for predicting mortality in the ICU: A systematic review. Crit Care, v. 12, n. 6, p. 161, 2008. https://doi.org/10.1186/cc7160 .

NASSER, Salem H. Fontes e normas do direito internacional, um estudo sobre a softlaw. 2. ed. São Paulo: Atlas, 2006.

NAVES, Bruno Torquato de Oliveira; REZENDE, Danúbia Ferreira Coelho. A autonomia privada do paciente em estado terminal. In: FIÚZA, C.; NAVES, B. T. O.; SÁ, M. F. F. Direito civil: atualidades II. Belo Horizonte: Del Rey, 2007. p. 105.

NUNES, Lucília. Ética em cuidados paliativos: limites ao investimento curativo. Revista Bioética, v. 16, n. 1, p. 41-50, 2008. Disponível em: http://revistabioetica.cfm.org.br/index.php/revista_bioetica/article/view/54. Acesso em: 4 maio 2020. 
PESSINI, Leo; BERTACHINI, Luciana. Humanização e cuidados paliativos. São Paulo: Loyola, 2004.

PIVA, Jefferson Pedro; GARCIA, Pedro Celiny Ramos; LAGO, Patrícia Miranda. Dilemas e dificuldades envolvendo decisões de final de vida e oferta de cuidados paliativos em pediatria. Rev. Bras. Ter. Intensiva, São Paulo, v. 23, n. 1, 2011. https://doi.org/10.1590/s0103-507x2011000100013.

RAYMUNDO, Marcia Mocellin; GOLDIM, José Roberto. Do consentimento por procuração à autorização por representação. Revista Bioética, v. 15, n. 1, p. 83-99, 2007. Disponível em: http://revistabioetica.cfm.org.br/index.php/revista_bioetica/article/ view/33. Acesso em: 7 maio 2020.

REIRIZ, André Barbas et al. Cuidados paliativos, a terceira via entre eutanásia e distanásia: ortotanásia. Prat. Hosp, v. 6, n. 48, p. 77-82, 2006.

SALIBA, Debra et al. The Vulnerable Elders Survey: a tool for identifying vulnerable older people in the community. J Am Geriatr Soc, v. 49, p, 1691-1699, 2003. https://doi.org/10.1034/j.1601-5215.2002.51030.x.

SANCHES, Kilda Mara Sanchez; SEIDL, Eliane Maria Fleury. Ortotanásia: uma decisão frente à terminalidade. Interface - Comunicação Saúde Educação, v. 17, n. 44, p. 23 34, 2013. https://doi.org/10.1590/s1414-32832013000100003.

SANTOS, André Filipe Junqueira. Cuidados paliativos na emergência. Revista Qualidade HC, 2017. Disponível em: http://www.hcrp.usp.br/revistaqualidade/uploads/Artigos/169/169.pdf. Acesso em: 7 maio 2020.

SCHIOCCHET, Taysa. Acesso e Exploração de Informação Genética Humana: da doação à repartição dos benefícios. 2010. 255 f. Tese (Doutorado em Direito) Programa de Pós-Graduação em Direito, Universidade Federal do Paraná, Curitiba, $2010 . \quad$ Disponível em: https://acervodigital.ufpr.br/bitstream/handle/1884/24288/Tese\%20final.pdf?sequen ce $=1 \&$ is Allowed $=y$. Acesso em: 7 maio 2020 .

SGRECCIA, Elio. Manual de bioética: fundamentos e ética biomédica. São Paulo: Loyola, 1996.

SHELTON, Dinah L. Soft Law. Handbook of International Law. George Washington University Law School. Routledge Press. 2008. Disponível em: https://scholarship.law.gwu.edu/cgi/viewcontent.cgi?article=2048\& context=faculty_pu blications. Acesso em: 21 ago. 2020. 
SILVA, Ronaldo Corrêa Ferreira da Silva; HORTALE, Virginia Alonso. Cuidados paliativos oncológicos: elementos para o debate de diretrizes nesta área. Cad. Saúde Pública, Rio de Janeiro, v. 22, n. 10, p. 2055-2066, 2006. https://doi.org/10.1590/s0102-311x2006001000011.

STEINHAUSER, Karen E. et al. Factors considered important at the end of life by patients, family, physicians, and other care providers. JAMA, v. 284, p. 2476-2482, 2000. https://doi.org/10.1001/jama.284.19.2476.

STOLZ, Camila et al. Manifestação das vontades antecipadas do paciente como fator inibidor da distanásia. Revista Bioética, v. 19, n. 3, 2011. Disponível em: http://revistabioetica.cfm.org.br/index.php/revista_bioetica/article/view/679. Acesso em: 5 maio 2020.

SZTAJN, Rachel. Terminalidade da vida: a ortotanásia e a constitucionalidade da res. CFM 1.805/2006. Revista de Direito Constitucional e Internacional, v. 17, n. 66, p. 245-257, 2009.

TABOADA, R. Paulina. El derecho a morir com dignidad [The right to die with dignity]. Acta Bioeth, v. 6, n. 1, p. 89-101, 2000. https://doi.org/10.4067/s1726$569 \times 2000000100007$.

VANE, Matheus Fachini; POSSO, Irimar de Paula. Opinião dos médicos das Unidades de Terapia Intensiva do Complexo Hospital das Clínicas sobre a ortotanásia. Rev. Dor, v. 12, n. 1, p. 39-45, 2011. Disponível em: https://www.scielo.br/scielo.php?script=sci_arttext\&pid=S1806-00132011000100009. Acesso em: 5 maio 2020.

VASCONCELOS, Thiago José Querino; IMAMURA, Natália Ramos; VILLAR, Heloísa Cesar Esteves Cerquira. Impacto da Resolução CFM 1.805/06 sobre os médicos que lidam com a morte. Revista Bioética, v. 19, n.2, p. 501-521, 2011. Disponível em: http://revistabioetica.cfm.org.br/index.php/revista_bioetica/article/viewFile/602/669. Acesso em: 5 maio 2020.

VÍTOR, Paula Távora. Procurador para cuidados de saúde: importância de um novo decisor. Lex Medicinae: Revista Portuguesa de Direito da Saúde, v. 1, n. 1, p. 121-134, 2004.

WIJDICKS, Eelco. Determining brain death in adults. Neurology, n.45, p.1003-1011, 1995. https://doi.org/10.1212/wnl.45.5.1003

WIJDICKS Eelco et al. Evidence-based guideline update: determining brain death in adults: report of the Quality Standards Subcommittee of the American Academy of 
Neurology. Neurology, v. 74, n. 23, p. 1911-1918, 2010. https://doi.org/10.1212/wnl.0b013e3181e242a8.

\section{NOTA}

A elaboração do presente artigo contou com a participação ativa de ambas as autoras para a construção do texto final. A primeira autora, Taysa Schiocchet, foi responsável pela concepção e desenho do estudo, limitação e abrangência do problema de pesquisa, definição de objetivo, análise e interpretação dos dados, redação e revisão crítica do manuscrito. A autora Suéllyn Mattos de Aragão, por sua vez, contribui com a pesquisa bibliográfica, análise e interpretação dos dados e redação.

\section{Como citar este documento:}

SCHIOCCHET, Taysa; ARAGÃO, Suéllyn Mattos de. A regulação do CFM e os desafios na aplicabilidade de Soft Law em casos de terminalidade. Revista Opinião Jurídica, Fortaleza, v. 19, n. 30, p. 1-34, jan./abr. 2021. 